\title{
Training Workshop on Environmental Economics and Policy Analysis
}

$\mathrm{T}$ he Harvard Institute for International Development (HIID) holds a five-weeks' intensive Training Workshop on Environmental Economics and Policy Analysis each summer at Harvard University, Cambridge, Massachusetts, USA. The primary goal of the Workshop is to train participants in the analysis, quantification, and economic valuation, of the environmental impact of policies, programmes, and projects. This year's Workshop will last from 21 June until 23 July.

Participants spend five weeks in an analytically rigorous, yet practical, Workshop, learning principles and policy-applications of environmental economics, and modern techniques of economic valuation of natural resources and the environment. Through lectures, casestudies, group discussions, and hands-on computer exercises, participants acquire the necessary skills for analysing, quantifying, and valuing, the environmental impacts of policies and projects. Particular attention is paid to integrating economic and environmental policies, and to devising innovative instruments for sustainable development and financing mechanisms for environmental investments.

\section{Topics covered include:}

Principles of Social Welfare Economics

Optimization Over Time

The Theory of Externalities

The Theory of Property Rights and Rents

The Economics of Pollution Control/Prevention

Market-based Instruments

Policy and Regulatory Instruments

Community Management of Resources

Environmental Valuation Methods

Measurement of Environmental Damage

Environmental Evaluation of Projects

The Economics of Sustainability

The Economics of Population Growth

Structural Adjustment and the Environment

Environmental Accounting

Global Environmental Problems.

Case-studies and application topics typically include land tenure, water pricing, energy efficiency, industrial pollution, urban congestion, pesticide management, ecotourism, fisheries management, forest concessions, watershed protection, financing of sustainable development, environmental taxation, structural adjustment, and trade liberalization.

The Workshop is designed to enhance the skills of midcareer development professionals who are interested or involved in natural resource management, environmental protection, and sustainable development. Participants will gain the tools that are necessary to evaluate, quantitatively, natural resources and the environment, and to formulate policies that will protect the environment without restricting economic growth. They should also acquire skills that are valuable for those working in government ministries, public enterprises, international organizations, private corporations, and nongovernmental organizations.

The Workshop is open to individuals holding a university degree in economics, agricultural economics, environmental science, forestry, engineering, mathematics, biology, ecology, or any field related to environmental economics. In order to follow the lectures, all participants must have an intermediate background in economics and some familiarity with quantitative methods.

HIID offers the Workshop as part of its Natural Resources and Environment Program, which includes teaching, research, and overseas technical assistance, in environmental management and sustainable development. The Workshop is partially funded by the Asia Bureau of the United States Agency for International Development (USAID) as part of a cooperative agreement with HIID. For further information please contact the undersigned.

ThEODORE PANAYOTOU, Program Director Environmental and Resource Economics Harvard Institute for International Development One Eliot Street

Cambridge

Massachusetts 02138 ,

USA.

Tel. (617) 495-9173

Fax (617) 495-0527

Cable: HIID, Cambridge, Massachusetts

Telex: 27276 (HIID UR)

\section{Stockholm Environment Institute}

$\mathrm{T}$ he Stockholm Environment Institute (SEI) was established by the Swedish Parliament in 1989 as an independent foundation for the purpose of carrying out global environment and development research. The Institute is governed by an international Board whose members are drawn from developing and industrialized countries world-wide.

Central to the Institute's work have been activities surrounding the Rio UNCED, and, previous to that, the Brandt and Palme Commissions and the work of the World Commission for Environment and Development. Apart from its working linkages with the relevant specialized agencies of the UN system, a particular feature of SEI's work programme is the role it has played in the development and application of Agenda 21, the muchdebated action plan for the next century.

A major aim of SEI's work is to bring together scientific research and policy development. The Institute applies scientific and technical analyses in environment and development issues of regional and global importance. The impacts of different policies are assessed, providing insights into strategy options for socially responsible environmental management and economic and social development.

The results of the research are made available through publications, the organization of and participation in conferences, seminars and university courses, and also through the development of software packages for use in the exploration of scientific problems. SEI has also developed a specialized library which functions as a central catalyst in the short-term and long-term work of the Institute.

\section{Research Programme}

A multidisciplinary rolling programme of research activities has been designed around the following main themes, which are being executed via internationally colla- 